\title{
Insulin-requiring diabetes in rural Ethiopia: should we reopen the case for malnutrition-related diabetes?
}

\author{
S. Alemu • A. Dessie • E. Seid • E. Bard • P. T. Lee • \\ E. R. Trimble • D. I. W. Phillips • E. H. O. Parry
}

Received: 23 March 2009 / Accepted: 4 June 2009 / Published online: 30 June 2009

(C) Springer-Verlag 2009

\begin{abstract}
Aims/hypothesis We evaluated the incidence of insulinrequiring diabetes in a rural area of sub-Saharan Africa.

Methods Health surveillance data from a chronic disease programme in two zones of Ethiopia, Gondar and Jimma, were studied. The two zones have a population of more than 5,000,000 people.

Results In Gondar Zone (1995-2008) and Jimma Zone (2002-2008) 2,280 patients presented with diabetes, of whom $1,029(45 \%)$ required insulin for glycaemic control at diagnosis. The annual incidence of insulin-requiring diabetes was $2.1(95 \%$ CI $2.0-2.2)$ per 100,000 and was twice as high in men $(2.9$ per 100,000) as in women $(1.4$ per 100,000). In both sexes incidence rates peaked at the age of 25 to 29 years. Incidence rates in the urban areas of Gondar and Jimma were five times higher than in the surrounding rural areas. Patients with insulin-requiring diabetes from rural and urban areas had a very low BMI and most were subsistence farmers or unemployed.
\end{abstract}

\footnotetext{
S. Alemu $\cdot$ A. Dessie

Department of Internal Medicine, Gondar University Hospital, Gondar, Ethiopia

E. Seid

Chronic Disease Programme, Jimma University Hospital,

Jimma, Ethiopia

E. Bard

St George's,

University of London,

London, UK

P. T. Lee

Internal Medicine, Massachusetts General Hospital,

Boston, MA, USA

Conclusions/interpretation The typical patient with diabetes in rural Ethiopia is an impoverished, young adult male with severe symptoms requiring insulin for glycaemic control. The low incidence rates in rural compared with urban areas suggest that many cases of this disease remain undiagnosed. The disease phenotype encountered in this area of Africa is very different from the classical type 1 diabetes seen in the West and most closely resembles previous descriptions of malnutrition-related diabetes, a category not recognised in the current WHO Diabetes Classification. We believe that the case for this condition should be reopened.

Keywords Diabetes · Ethiopia · Incidence Insulin-dependent diabetes $\cdot$ Malnutrition

\section{Abbreviation \\ IQR Interquartile range}

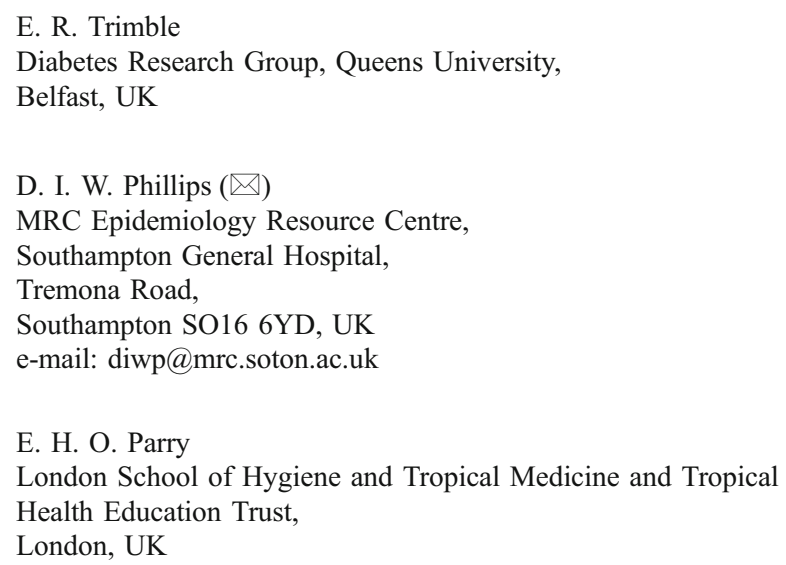




\section{Introduction}

Little is known about the occurrence of insulin-requiring diabetes in sub-Saharan Africa. While available incidence data are confined to studies of the under-20-year-old age group in major cities $[1,2]$, there are suggestions that its epidemiology is very unlike that found in the West, with widespread occurrence of atypical forms [3]. We therefore analysed surveillance data collected during a chronic disease programme in Ethiopia to determine the incidence of insulin-requiring diabetes in two large rural areas of that country.

\section{Methods}

The study was carried out in Ethiopia, a resource-poor country, ranked 171 st of 174 countries according to the Millennium United Nations Development Programme's Human Development Index. The country experienced severe famines in 1972 to $1974,1978,1984$ to 1985 , 1987 to 1988 and 1990 to 1992 and more than 50\% of children have nutritional stunting. The estimated prevalence rate of diabetes in the adult population is $1.9 \%$ [3]. We obtained data from clinics providing unique diabetes services to two predominantly rural zones of Ethiopia: Gondar and Jimma, $750 \mathrm{~km}$ northwest and $330 \mathrm{~km}$ southwest of the capital, Addis Ababa, respectively. Each zone has a central university hospital together with health centres serving the surrounding rural population. The study included all diabetic patients presenting in Gondar zone (mid-study population 2,600,884) between 1995 and 2008, and all those presenting in Jimma Zone (population 2,434,025) between 2002 and 2008. Insulin-requiring diabetes was defined as diabetes requiring insulin treatment from diagnosis. The clinic records included data on village of residence, age and sex. The patients' weight, height and occupation were additionally available in the Gondar clinic. The BMI was calculated as weight in $\mathrm{kg} /$ height in $\mathrm{m}^{2}$. Patients living outside the two zones were excluded from the study. Population data were derived from national censuses carried out in 1993 and 2007, and interpolated population estimates were used to calculate indirectly ageand sex-standardised incidence rates together with 95\% CIs based on the Poisson distribution.

\section{Results}

During the study period a total of 2,280 diabetic patients presented in the two zones, of whom 1,029 (45\%) required insulin for glycaemic control at diagnosis. The overall annual incidence of insulin-requiring diabetes was 2.1 (95\%
CI 2.0-2.2) per 100,000 and was similar in both zones (Gondar 2.2, Jimma 2.0 per 100,000). In comparison the annual incidence of patients presenting with non-insulin requiring (type 2) diabetes was 2.6 per 100,000 .

The annual incidence in men, 2.9 (2.7-3.1) per 100,000, was twice as high as that in women (1.4 [1.3-1.6] per 100,000). Figure 1 shows the age- and sex-specific incidence rates of presenting patients. In both sexes incidence peaked at age 25 to 29 years and then declined, with a median age at presentation of 25.5 (interquartile range [IQR] 20.0-32.0) years in men and 27.5 (IQR 19$35.5)$ years in women. Only 34 cases (3.3\% of the total) were diagnosed under the age of 15 years. The male excess was more marked in the 15- to 40-year age group (sex ratio 2.4:1) than in those diagnosed at younger than 15 years (sex ratio $1.2: 1$ ) or at more than 40 years of age (sex ratio 1.1:1). Among the patients with type 2 diabetes, the sex ratio was $1.2: 1$.

Table 1 compares the annual incidence of insulinrequiring diabetes in the small urban areas of Gondar and Jimma with the incidence in the large surrounding rural areas. For comparison, data on patients presenting with type 2 diabetes are also shown. The greater incidence among males was observed in urban and rural areas. The urban incidence was over five times higher than the rural incidence in both sexes $(p<0.001)$. The median age at presentation was somewhat higher in rural patients than in urban cases, particularly among women. Among adults aged 18 or more in the Gondar study, the BMI of urban and rural cases was low, but was extremely low among the rural cases ( $p<0.001 \mathrm{vs}$ urban cases) with a mean in both sexes of less than $17 \mathrm{~kg} / \mathrm{m}^{2}$. In contrast, patients with type 2 diabetes were much older, mainly lived in urban areas and had a much higher BMI.

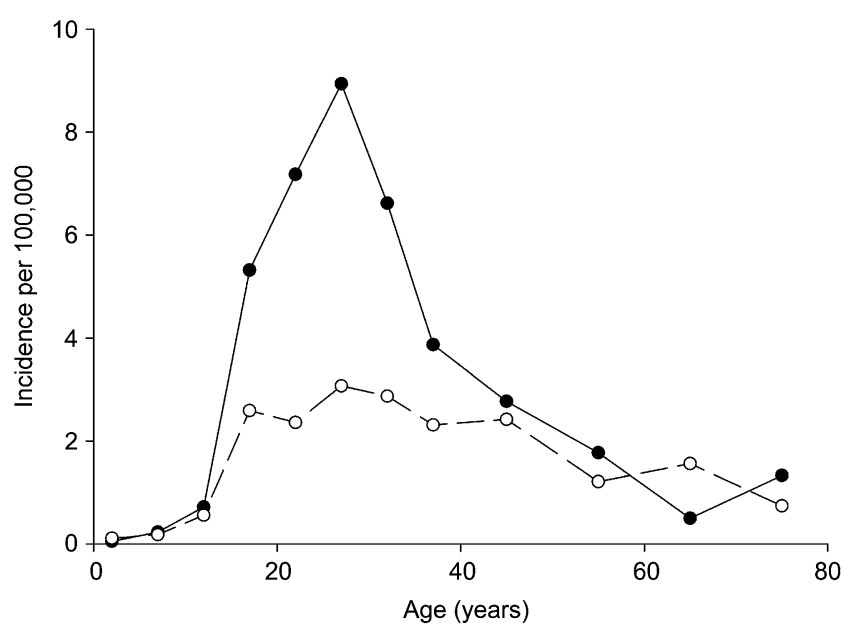

Fig. 1 Age- and sex-specific incidence of insulin-requiring diabetes in the Gondar and Jimma zones of Ethiopia. Black circles, men; white circles, women 
Table 1 Comparison of patients with diabetes who at presentation were resident in the urban centres of Gondar and Jimma with those resident in the surrounding rural areas
Case records were incomplete for eight patients

${ }^{\text {a }}$ Numbers represent 13 years of data in Gondar Hospital and 6 years of data in Jimma hospital

${ }^{\mathrm{b}}$ Adults aged 18 years or more in the Gondar study

\begin{tabular}{|c|c|c|}
\hline Variables & Urban & Rural \\
\hline Population $\left(\times 10^{3}\right)$ & 321.5 & $4,713.4$ \\
\hline \multicolumn{3}{|c|}{ Insulin-requiring diabetes } \\
\hline Cases $(n)^{\mathrm{a}}$ & 314 & 715 \\
\hline \multicolumn{3}{|c|}{ Annual incidence per $10^{5}(95 \% \mathrm{CI})$} \\
\hline Men & $11.9(10.3-13.7)$ & $2.2(2.0-2.4)$ \\
\hline Women & $6.1(5.0-7.3)$ & $1.0(0.9-1.1)$ \\
\hline \multicolumn{3}{|c|}{ Median age at presentation (IQR) } \\
\hline Men & $25.0(20.0-30.5)$ & $25.5(20.5-32.5)$ \\
\hline Women & $25.0(17.5-35.5)$ & $28.0(20.0-36.0)$ \\
\hline \multicolumn{3}{|l|}{$\mathrm{BMI} \mathrm{kg} / \mathrm{m}^{2}(\mathrm{SD})^{\mathrm{b}}$} \\
\hline Men & $18.4(3.3)$ & $16.7(2.2)$ \\
\hline Women & $19.4(3.6)$ & $16.5(3.1)$ \\
\hline \multicolumn{3}{|c|}{ Non-insulin requiring (type 2 ) diabetes } \\
\hline Cases $(n)^{\mathrm{a}}$ & 846 & 397 \\
\hline \multicolumn{3}{|c|}{ Annual incidence per $10^{5}(95 \% \mathrm{CI})$} \\
\hline Men & $28.5(25.9-31.2)$ & $1.1(0.9-1.2)$ \\
\hline Women & $24.8(22.4-27.4)$ & $0.6(0.5-0.8)$ \\
\hline \multicolumn{3}{|c|}{ Median age at presentation (IQR) } \\
\hline Men & $50.5(42.5-60.0)$ & $50.0(44.0-60.0)$ \\
\hline Women & $50.0(40.5-58.5)$ & $50.0(42.0-62.5)$ \\
\hline \multicolumn{3}{|l|}{ BMI $\mathrm{kg} / \mathrm{m}^{2}(\mathrm{SD})^{\mathrm{b}}$} \\
\hline Men & $23.3(3.2)$ & $20.7(3.7)$ \\
\hline Women & $25.0(4.8)$ & $21.7(5.9)$ \\
\hline
\end{tabular}

\section{Discussion}

This is the first study documenting the incidence of insulinrequiring diabetes in rural communities in sub-Saharan Africa. Although there are no comparable studies, a survey from Dar es Salaam, Tanzania, [2] reported an incidence of 1.5 per 100,000 in the 0 - to 19 -year age group and one in Khartoum, Sudan, 7.9 per 100,000 in the 0 - to 15 -year age group [1]. However, the Ethiopian rates seem disproportionately low compared with the overall type 1 diabetes incidence for the USA, which was 11.8 per 100,000 [4], suggesting that the true numbers of patients with insulinrequiring diabetes may be much higher. This is also suggested by the finding that urban incidence rates were over five times higher than the rural rates. Local enquiries established that this was only rarely due to patients moving to live in the vicinity of the two university hospitals to obtain treatment. It is likely that many diabetic patients in rural areas are either not presenting to the clinics or have already died from complications of their disease as a result of the barriers to accessing care. Insulin-requiring diabetes was by far the most common form of diabetes presenting in rural areas; of 1,114 rural patients with diabetes, 715 (64.2\%) were insulin-requiring.

Although classified as having type 1 diabetes on the basis of their insulin requirement at diagnosis, these
Ethiopian patients clearly differ from the type 1 diabetes phenotype encountered in Western populations in three ways. These are the age of onset, male predominance and socioeconomic background.

The data from Ethiopia (Fig. 1) show peak incidence in both sexes between the ages of 25 and 29 years. Only 34 cases in our Ethiopian cohort $(3.3 \%$ of the total) were diagnosed under the age of 15 years. These findings contrast with data from diabetes registries in the USA, Europe and Japan, which show that incidence peaks at the age of puberty, with a lesser peak in young children aged 0 to 4 years [4]. This late age of presentation has also been reported in other African studies [5,6].

The incidence in men was twice that in women, a finding that was present in urban and rural populations (Table 1) and was particularly evident in the 15 to 40 age group, but not in younger or older patients. This higher male incidence was also much less evident among the type 2 patients who attended the same clinics. Although it could be due in part to male patients having preferential access to medical care, our data are consistent with the findings of previous studies $[6,7]$ and may have a biological basis, although one that is not clear. The excess of men contrasts with findings in conventional type 1 diabetes, where sex ratios are close to unity with a slight female excess in non-white populations [4]. 
Finally, while in the West, type 1 diabetes tends to be a disease of the advantaged [8], our data show that Ethiopian patients from Gondar are very poor and have an extremely low BMI, especially in rural areas (Table 1). In the Gondar population of 358 men with insulin-requiring diabetes whose occupation was recorded, 256 (71.5\%) were subsistence farmers or unemployed, while only $35(9.8 \%)$ were employed in business or receiving salaries. Insulinrequiring diabetes represents a severe hardship to these patients because of the expense of insulin, frequent interruptions in its supply and the consequent difficulty in maintaining good glycaemic control.

Our data suggest that a large proportion of insulinrequiring patients in this rural Ethiopian cohort have a form of diabetes not recognised by the current WHO classification. The disease is similar to the malnutrition-related diabetes first described by Hugh-Jones in Jamaica [9], but since reported widely in both the Indian subcontinent and Africa [3, 7]. A history of childhood malnutrition is often present [7]. In Ethiopia, in other countries [3, 7] and in Rwanda where one of us has investigated a similar population (P.T. Lee, unpublished observations), these patients present with an insidious onset of severe symptoms (emaciation, polydipsia and weakness), but only rarely develop ketoacidosis, possibly indicating sufficient residual insulin secretion to suppress lipolysis, but not enough to prevent postprandial hyperglycaemia. Exocrine pancreatic abnormalities associated with pancreatic calcification, which have been linked with diabetes in some parts of Africa, are not found in patients in Ethiopia [10], and the little available data suggest that genetic or phenotypic markers of islet cell autoimmunity are only rarely seen $[3,7]$, although recent data from India suggest that some people with the condition have genetic and humoral markers of autoimmunity suggestive of a form of slowly progressive type 1 diabetes [11].

In 1985, the WHO Study Group on Diabetes recognised malnutrition-related diabetes mellitus (MRDM) as a separate entity [12], but this was revoked in the 1999 classification [13]. We propose reopening the case for malnutrition-related diabetes. If this type of diabetes proves to be strongly associated with a history of prior and/or ongoing malnutrition, appropriate management strategies would include addressing patients' social determinants of health, including poverty, food insecurity and access to health services. From a public health perspective, we believe malnutrition-related diabetes may be an important, unrecognised cause of morbidity, mortality and economic loss in rural Africa, and should qualify as one of Africa's neglected diseases.

Acknowledgements The work was supported by private donations to the Tropical Health Education Trust and by a grant from the Association of Physicians of Great Britain and Ireland. We are grateful to I. Reading, MRC Southampton, for statistical advice.

Duality of interest The authors declare that there is no duality of interest associated with this manuscript

\section{References}

1. Elamin A, Omer MI, Zein K, Tuvemo T (1992) Epidemiology of childhood type I diabetes in Sudan, 1987-1990. Diabetes Care 15:1556-1559

2. Swai ABM, Lutale JL, McLarty DG (1993) Prospective study of incidence of juvenile diabetes mellitus over 10 years in Dar es Salaam, Tanzania. BMJ 306:1570-1572

3. Gill GV, Mbanya JC, Ramaiya KL, Tesfaye S (2009) A subSaharan African perspective of diabetes. Diabetologia 52:8-16

4. LaPorte R, Matsushima M, Chang Y-F (1995) Prevalence and incidence of insulin-dependent diabetes. In: National Diabetes Data Group (ed) Diabetes in America, 2nd edn. NIH, Bethesda, pp $37-46$

5. Kalk WJ, Huddle KR, Raal FJ (1993) The age of onset and sex distribution of insulin-dependent diabetes mellitus in Africans in South Africa. Postgrad Med J 69:552-556

6. Habtu E, Gill G, Tesfaye S (1999) Characteristics of insulin requiring diabetes in rural northern Ethiopia - a possible link with malnutrition? Ethiop Med J 37:263-267

7. Abu-Bakare A, Taylor R, Gill GV, Alberti KG (1986) Tropical or malnutrition-related diabetes: a real syndrome? Lancet 1:11351138

8. Cowie CC, Eberhardt MS (1995) Sociodemographic characteristics of persons with diabetes. In: National Diabetes Data Group (ed) Diabetes in America, 2nd edn. NIH, Bethesda, pp 85-116

9. Hugh-Jones P (1955) Diabetes in Jamaica. Lancet 269:891-897

10. Lester FT, Abdulkadir J, Larson D, Quana'a P (1976) Diabetes mellitus: clinical features in 404 Ethiopians. Ethiop Med J 14:185-198

11. Kanungo A, Samal KC, Sanjeevi CB (2002) Molecular mechanisms involved in the etiopathogenesis of malnutrition-modulated diabetes mellitus. Ann N Y Acad Sci 958:138-143

12. World Health Organization (1985) Diabetes mellitus: report of a WHO study group. Technical Report Series no. 727. WHO, Geneva,

13. World Health Organization (1999) Definition, diagnosis and classification of diabetes mellitus and its complications. WHO, Geneva 